\title{
Strength characterization of glass/epoxy plain weave composite under different biaxial loading ratios
}

\author{
A. Kobeissi ${ }^{a^{*}}$, P. Rahme ${ }^{b}$, L. Leotoing ${ }^{a}$, D. Guines ${ }^{a}$ \\ a Univ Rennes, INSA Rennes, LGCGM (Laboratoire de Génie Civil et Génie Mécanique) - EA 3913, \\ F-35000 Rennes, France \\ ${ }^{\mathrm{b}}$ Lebanese University, Faculty of Engineering, Mechanical Engineering Department, Roumieh-Metn, \\ Lebanon
}

\begin{abstract}
Over the past years, various studies have been investigated in order to characterize the behavior of composite materials under different multi-axial loading conditions. One of the most used biaxial techniques is the in-plane biaxial test on cruciform specimens. To achieve reliable biaxial failure results, the design of the cruciform specimen presents a crucial part. Previous studies show that there is no welladapted cruciform geometry for the composite biaxial tests. In this paper, an optimal cruciform specimen has been defined numerically for the composite characterization test. The specimen is composed of two aluminum tabs glued on top and bottom side of the plain-weave glass/epoxy composite. Finite element simulations have been carried out in order to study the influence of the aluminum grade and thickness on the stress distribution in the composite. An experimental validation confirms the failure of the specimen in the central zone under three different biaxial tensile ratios. The experimental strains were evaluated using the digital image correlation method. The traction/traction quadrant of the failure envelop was obtained and compared with different failure criteria. The maximum strain criterion shows a good agreement with the experimental results.
\end{abstract}

Keywords: Biaxial test, strain path, failure envelop, cruciform specimen.

* Corresponding author address: INSA-LGCGM-EA3913, 20 Av.des Buttes de Coësmes, CS 70839, 35708 Rennes Cedex 7, France. Tel.: + 33223238376.

Email address: alaa.kobeissi@insa-rennes.fr (A. Kobeissi) 


\section{Introduction}

In the last decades, the composite material becomes widely used in various industries (aeronautic, aerospace, transportation ...) due to its high specific mechanical properties. Although composites present many benefits compared to traditional materials, mechanical characterization and computation of composite structures are not straightforward due to the complexity of these materials. This is particularly true in the case of continuous fiber composites consisting of two phases (fibers and matrix) and of several laminae stacked in different directions leading to strong anisotropic mechanical behavior [1]. Usually, the conventional uniaxial test is used to identify materials properties. However, this kind of tests is unable to identify the real behavior of composite materials which strongly depends on the loading state during engineering applications. A solution to improve the mechanical behavior identification is to use the biaxial test. In fact, it presents a high performance to identify material properties by performing a single test instead of multiple uniaxial tests [2]. In addition, it allows the application of biaxial loadings, closer to the real conditions encountered by the composite structure. In the literature, different biaxial testing methods have been proposed [3]. The two most used biaxial methods are (i) test on tubular specimens and (ii) inplane biaxial test on cruciform specimens. The biaxial test on tubular specimens was recently used by various researchers since it resolves the problem of the edge effect found in the flat specimens [4]. However, different researchers show that the biaxial test on tubular specimens induces an effective through thickness stress which limits the characterization of composite materials for only tubular applications [5-6]. On the other hand, the use of flat composites in engineering applications and the simplicity of varying the biaxial stress state in the material make the in-plane biaxial test on cruciform specimen one of the most adapted methods compared to tubular specimens. Nevertheless, biaxial testing involves many difficulties especially related to the definition of geometrical specimen shape.

In the literature, several cruciform shapes have been designed for the characterization of sheet metals subjected to biaxial loading [7]. Depending on the mechanical behavior to be identified (fatigue strength, 
forming or rupture limits, hardening law, yield surface ...), several flat specimen shapes have been proposed during the last years [8]-[10]. Recently, the international standard ISO 16842 has been proposed for flat sheet metal uniform thickness in order to obtain the contours of plastic work [11].

For composite material, the design of an adapted cruciform shape trends to be more difficult and complicated compared to metals since fiber-reinforced composites are sensitive to the local stress concentration [12]. Moreover, the particular failure modes (e.g. first ply failure, delamination ....) and the complex stress state in each layer make the analysis of the biaxial behavior of the specimen more complicated. Previous studies have shown that to obtain failure in the biaxially loaded central zone, a maximum homogeneous stress state should be reached in this area. To achieve this, a thickness reduction must be applied in the center of the cruciform specimen. Two methods have been used in order to reduce the thickness of the specimen in the central zone. The first method is by sandwiching the studied composite (e.g. carbon/epoxy) between two layers of different composite (e.g. glass/epoxy) with a hole in the center in order to form a complete reduced thickness specimen. This method, which has been successfully tested on large thick specimens, requires a high loading capacity machines. On this concept, Hopgood [13] obtained the failure envelope of open-holes carbon fiber reinforced epoxy by performing biaxial tests (machine capacity of $500 \mathrm{kN}$ ). The specimen was made of $2 \mathrm{~mm}$ thick carbon/epoxy composite sandwiched between two layers of glass/epoxy composite. Williamson et al. [14] also studied the biaxial failure of open-hole carbon/epoxy cruciform specimen. The specimen was tested under different biaxial tension and compression ratios in order to cover the whole failure envelop of the material. The specimen thickness reduction was also made by adding two layers of $4 \mathrm{~mm}$ thick quasi-isotropic glass/epoxy composite on both sides of the carbon composite. In this study, different hole diameter, specimen thickness and layup orientation were investigated. The biaxial testing machine used in this study has a capacity of $1500 \mathrm{kN}$. The maximum load reached was $1124 \mathrm{kN}$ for a $10 \mathrm{~mm}$ thick carbon specimen with a $6 \mathrm{~mm}$ hole diameter. In addition, Escarpita et al. [15] proposed a large cruciform specimen with a rhomboidal central zone where a homogeneous stress state is generated in the gauge area. The thickness 
reduction of the gauge area was performed during the manufacturing process of the cruciform specimen in order to avoid the milling process. Reinforcement layers (tabs) with a rhomboidal hole were impregnated with the central layer to obtain the final specimen shape. The failure strains of a single layer plain weave glass/epoxy composite (thickness of $0.2 \mathrm{~mm}$ ) are measured using the digital image correlation technique for three different biaxial loading conditions $(1: 1,1: 1.25$, and 1:1.5).

The second thickness reduction method is by milling a specific number of plies using a CNC machine while the remaining plies in the center define the studied composite. Welsh and Adams [16] studied the shape of the IM6/3501-6 carbon/epoxy cross-ply cruciform specimen. They analyzed the influence of the fillet radius between the cruciform arms and the shape of the central zone (square or circle) on ultimate stresses. In order to avoid the use of strain gages for the stress calculation for each experimental test, an area correction factor is defined as the amount of load transmitted from the arms towards the central zone. The complete failure envelop has been obtained during this study where the optimal specimen was the one with a square central zone. Welsh [17] also studied the biaxial failure of carbon fiber IM977-2 epoxy matrix quasi-isotropic laminate. The same previously defined shape is used with a specimen ply sequence $\left[(0 / 90)_{4} /(0 /+45 /-45 / 90)_{2}\right]_{\mathrm{s}}$. The thickness reduction is made by milling the $(0 / 90)$ portions from the top and bottom of the specimen. The failure envelop was also compared with two well-known isotropic failure criteria (Maximum Shear Stress and Von Mises). Smits et al. [18] proposed another cruciform specimen where the composite studied is $\left[( \pm 45 / 0)_{4} / \pm 45\right]_{\mathrm{T}}$ glass/epoxy. The thickness reduction was made by milling $( \pm 45 / 0)$ plies from both sides of the central zone. Smits performed a numerical study on the shape of the corner fillet between the loaded arms of the cruciform specimen. An experimental validation (using digital image correlation) shows that the specimen with adapted corner fillet from outside the arms towards inside gives better strain distribution in the central zone. The selected shape was tested under different biaxial tensile ratios in order to obtain the failure envelop of the material. Makris et al. [19] compared the results obtained on Smits optimized specimen with different failure criteria. The first ply failure prediction was used. The comparison shows that Tsai's criterion is more accurate compared to 
other predictions such as Max Stress and PUCK criterion. Moreover, Makris et al. [20] studied the failure of a cross-ply carbon epoxy cruciform specimen under quasi-static biaxial test. The layup used in their study was $\left[(90 / 0)_{2},(0 / 90)_{2}\right]$ s where one group of $\left[(90 / 0)_{2}\right]$ was milled away in order to reach the failure in the central region. The digital image correlation technic (DIC) has been used for the biaxial strain measurements. Makris used a progressive damage modeling to predict the failure of the composite. Hashin failure criterion is used for the matrix, fiber compression and delamination failure modes, while the Maximum Stress is adopted for the fiber tension failure. A good correlation is obtained between experimental and numerical strain field results in the central area.

Ramault et al. [21] compared the results of biaxial tests performed on specimens produced either by milling or by sandwiching. This comparison was proposed to evaluate the influence of the manufacturing process on the mechanical properties or the damage behavior of the studied composite. For sandwich specimens, failure did not occur in the central zone and a premature failure is obtained because of delamination corresponding to the debonding of the tabs caused by interlaminar shear strains between the upper lamina of the central area and the lower lamina of the tab. Lower failure loads were obtained for the specimens with tabs compared to the milled one. In addition, Lamkanfi [22] studied the effect of geometrical discontinuities (generated by milling) on the strain distribution in the specimen. A strain concentration was noticed between the milled central zone and the un-milled surrounding area. The results show that milling the specimen has a major influence on the premature failure of the composite specimen where a crack was always presented at the transition zone regardless the type of the load and the loading direction. Moreover, Ash and Welsh [23] also compared the results obtained from both thickness reduction methods : sandwiching (builtup specimens) and milling (standard specimens). The composite is a carbon/epoxy with $\left[(0 / 90)_{4}\right] \mathrm{s}$ stacking sequence (IM7/977-2), the shape of the cruciform specimen is the one developed previously by Welsh and Adams [16]. The results show that for the built-up specimen, the failure occurred in the narrow section of the arm right next to the gage section for all biaxial tensile. Torres and Maji [24] studied the strength of $\left[(0 / 90)_{8}\right] \mathrm{s} 6.35 \mathrm{~mm}$ thick woven carbon/epoxy composite. The shape of the specimen with a curved fillet between the arms and a square central gage section was based 
on the study of Welsh and Adams [16]. To reduce the stress concentration in the corners without milling the central zone, aluminum shims have been added on the corner fillets. Results show that an undesirable fracture occurred outside the central zone, near the (end of shims). Based on the previous results, Torres defined a new specimen by gluing glass/epoxy tabs on both sides of the composite, similar to the one of Ash and Welsh [23]. The main difference between the two studies is the adhesive type between the carbon plate and the glass/epoxy tabs. For the second case, the adhesion is performed by curing an adhesive film (Hysol) instead of hand spreading, in order to decrease the trapping air. It was mentioned that the failure starts in the central zone and propagates to the arms.

Since most of the previous studies focus on the failure of the composite, the failure envelop was always an interesting way to present the ultimate stresses of the material under different biaxial ratios. The experimental failure envelop is used to validate different analytical failure criteria. In 2004, the first world-wide failure exercise (WWFE-I) was done where 19 different failure theories were presented and compared with experimental tests under 2D stress state. As results, some of the theories were modified and improved for the first time after 40 years. However, it was concluded that there is a lack in the failure prediction of composite materials under multiaxial stress state [25]. Based on that conclusion, the second world-wide failure exercise (WWFE-II) was performed, the study focuses on the failure characterization of composites under tri-axial stress state. However, the same conclusion was obtained and only a few theories could give acceptable correlation (within $\pm 50 \%$ ) with test data for $75 \%$ of the test cases [26].

According to the literature, the characterization of composite materials under multi-axial loading is still a challenge. Up to now, there is no standardized specimen shape to characterize composites, particularly continuous fiber composites. In this paper, an optimal cruciform specimen shape for the biaxial tensile test of plain-weave glass/epoxy composite is proposed. Based on the previous studies, the idea of milling the central zone of the composite is avoided and a new concept is proposed by gluing aluminum tabs on both sides of the constant thickness composite plate. The thickness reduction is made only in the aluminum tabs 


\section{Composite cruciform specimen shape}

The composite characterized in this study is a four laminae plain-weave glass/epoxy composite with a total thickness of $1 \mathrm{~mm}(0.25 \mathrm{~mm}$ lamina thickness). Table 1 shows the glass/epoxy elastic properties obtained from uniaxial tests performed on tensile specimens with standard dimensions.

Table 1. Glass/epoxy plain-weave material properties

\begin{tabular}{ccccc} 
Material & $\mathbf{E}_{\mathbf{x}}(\mathbf{G P a})$ & $\mathbf{E}_{\mathbf{y}}(\mathbf{G P a})$ & $\mathbf{G}_{\mathbf{x y}}(\mathbf{G P a})$ & $\mathbf{v}_{\mathbf{x y}}$ \\
\hline GFRP & 22.8 & 22.8 & 4.1 & 0.14 \\
\hline
\end{tabular}

\subsection{Definition of the aluminum tabs}

As previously mentioned in the literature, a reduced thickness of the cross specimen central part is needed to ensure stress/strain localization in this zone. For that, it has been chosen in this work to use aluminum tabs including central thickness reduction glued on both sides of the constant thickness composite. Aluminum tabs, are preferred over composite tabs mainly for different reasons: (i) by milling, it is possible to obtain easily accurate and complex shapes for the transition zone, between the specimen center and the arms, where a reduction in thickness is needed, (ii) avoid the risk of delamination in the tabs, especially if the thickness reduction in the composite is obtained by machining, (iii) allow to reach higher strain levels in the tabs (with plastification) compared to the composite which ensure the failure in the central zone of the composite before the tabs. 
It should be noted that the length $(\mathrm{L}=160 \mathrm{~mm})$ is mainly defined by the available working space of the machine and the choice of the width of the specimen arms $(\mathrm{H}=18 \mathrm{~mm})$ is directly related to the maximum force capacity of the machine $(50 \mathrm{kN})$.

The choice of the central shape and the determination of its characteristic dimensions have been defined previously by means of a parametric study based on FE simulations of the equi-biaxial tensile test [27]. Based on these numerical investigations, a central hole with a diameter of $15 \mathrm{~mm}$ and a corner radius of $18 \mathrm{~mm}$ between two adjacent arms are obtained as optimal parameters (Figure 1), while the radius of the transition zone of the thickness is $17.1 \mathrm{~mm}$.
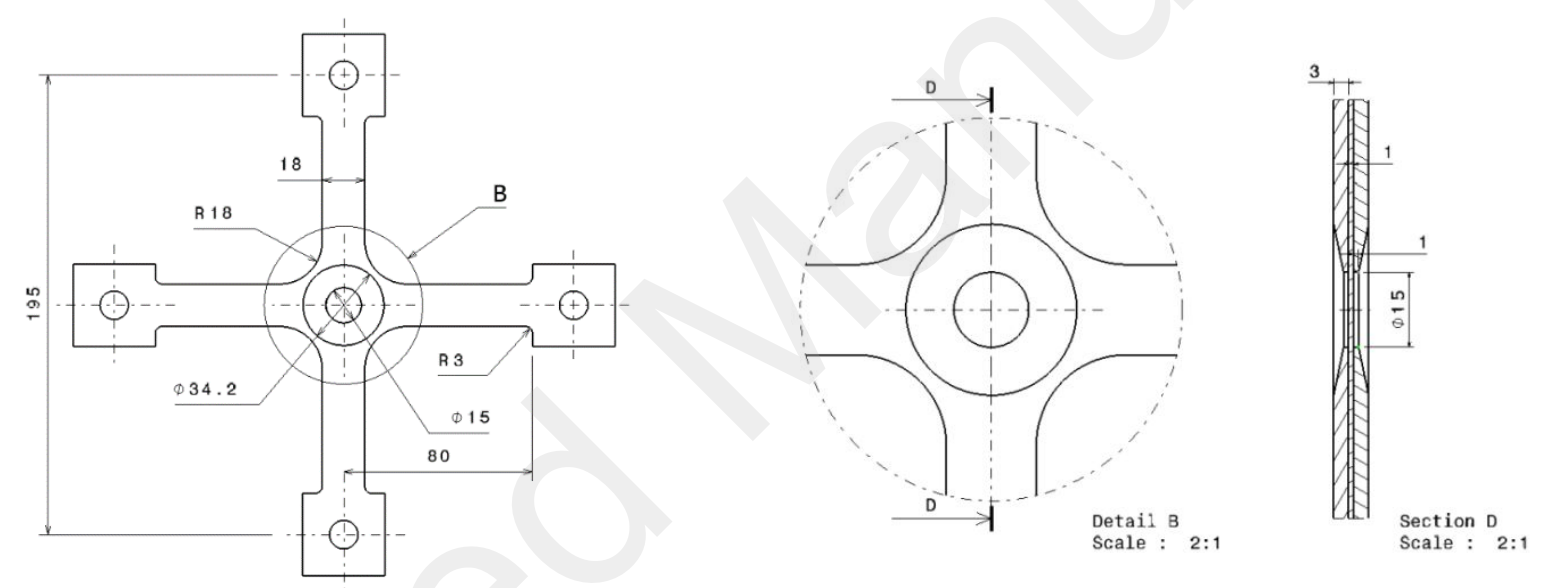

Figure 1. Dimensions of the sandwich cruciform specimen (in $\mathrm{mm}$ )

Numerical analysis are carried out using ABAQUS software. Since the specimen is symmetric, one-fourth of the specimen is only modeled (Figure 2). Considering the meshing, a C3D8R hexahedral mesh has been used for the aluminum and composite parts while the cohesive has been meshed using the three dimensional cohesive element COH3D8. In the composite thickness, eight elements are defined. A tie constraint has been generated between the cohesive and its surrounding surfaces. An equi-biaxial tensile test is generated by applying a $1 \mathrm{~mm}$ displacement on the end of each cruciform arm. The thickness of the aluminum tabs is reduced from $3 \mathrm{~mm}$ (arms thickness) to $1 \mathrm{~mm}$ (at the radius of $7.5 \mathrm{~mm}$ from the center of the specimen as shown in Figure 2). 


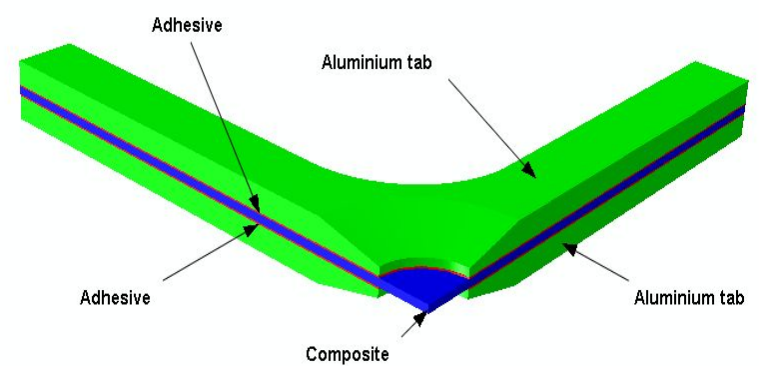

(a)

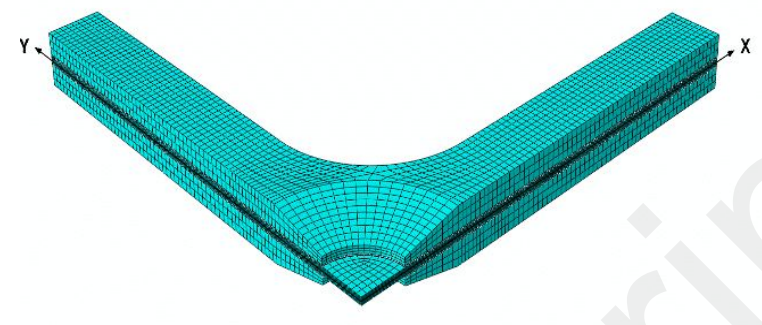

(b)

Figure 2. Numerical model (a) and 3D meshing (b) of the cruciform specimen using ABAQUS

Based on this FE model, various numerical simulations are carried out in order to evaluate both the influence of the mechanical characteristics and the dimensions (thickness) of the tabs on the overall behavior of the specimen and in particular on its ability to generate the composite failure in the central zone.

With regard to the mechanical behavior of the tabs, two grades of aluminum alloy (AA2017 and AA5086) with very different initial yield strengths (and ultimate stress) are evaluated numerically. Table 2 shows the initial yield and ultimate stresses for the two aluminum alloys which are considered to have the same Young modulus $(E=70 \mathrm{GPa})$ and Poisson ratio $(v=0.3)$. The adhesive used between the aluminum tabs and the composite is a multi-material epoxy adhesive $(E=2.1 \mathrm{GPa}$ and $G=769 \mathrm{MPa})$. Regarding the thickness, two values of $3 \mathrm{~mm}$ and $5.5 \mathrm{~mm}$ are considered here.

Table 2. Yield and ultimate stresses for aluminum alloy AA2017 and AA5086

\begin{tabular}{ccc} 
Aluminum & Yield Stress (MPa) & Ultimate Stress (MPa) \\
\hline AA5086 & 126 & 400 \\
\hline AA2017 & 230 & 534 \\
\hline
\end{tabular}




\subsection{Effects of tabs material and thickness}

The first part in this section consists of comparing the effect of the aluminum alloy used for the tabs on the stress distribution in the composite. Since the test is symmetric, only the x-direction stress distribution $\sigma_{X X}$ in the composite, when a displacement of $1 \mathrm{~mm}$ is applied, is presented (Figure 3). The results show that the use of AA2017 gives higher stresses $\left(\sigma_{X X}=480 \mathrm{MPa}\right)$ in the central zone of the composite compared to AA5086 $\left(\sigma_{X X}=380 \mathrm{MPa}\right)$. On the contrary, in the arms, both identical stress distributions and maximum stress values are observed. In addition, a small difference is noticed between the stresses in the central zone (380 MPa) and the stresses in the loading arms (320 MPa) for the specimen with AA5086 tabs which increase the possibility of the premature failure in the loading arms instead of the central zone.

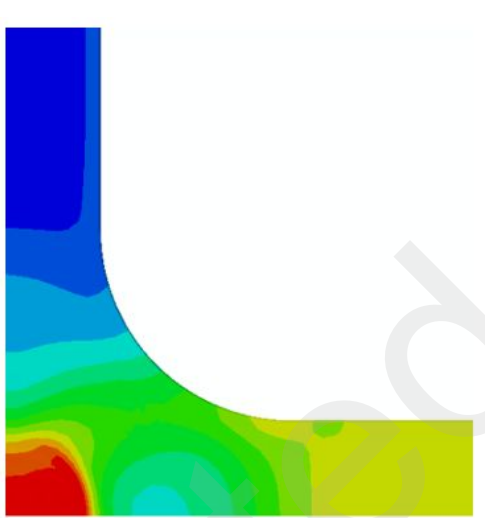

(a)

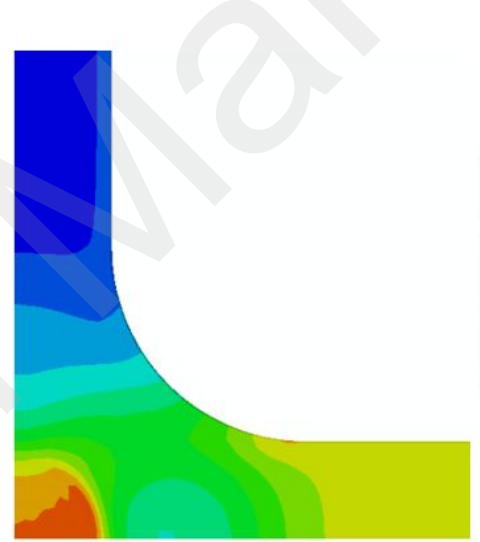

(b)

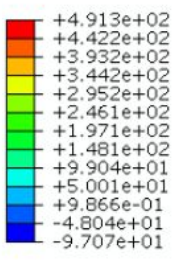

Figure 3. $\sigma_{X X}(M P a)$ in composite using (a) AA2017 and (b) AA5086 tabs

Moreover, a comparison between the equivalent plastic strain (PEEQ) distribution in the aluminum tabs is shown in Figure 4. The comparison is made when the same level of stresses is reached in the composite using both aluminum tabs (stress level of $350 \mathrm{MPa}$ ). It is clearly noticed that a lower plastic strain is reached in the AA2017 (1.6\%) compared to AA5086 (1.9\%). The high plastic strain increases the possibility of debonding of the aluminum tabs (adhesive failure) which will lead to an undesirable failure in the loading arm of the composite. According to these results, it is important to use the aluminum alloy 
In addition, the effect of the tab thickness on the stresses in the central zone has been made numerically using two different aluminum AA5086 thicknesses ( 3 and $5.5 \mathrm{~mm}$ ). The same boundary conditions have been imposed with a $1 \mathrm{~mm}$ displacement on both cruciform arms. Figure 5 shows that the use of a thicker aluminum tab increases the stress level in the composite central zone. Note that, increasing the thickness of the aluminum will increase the load required by the machine in order to reach the failure of the composite.

Figure 4. Equivalent plastic strain (PEEQ) for (a) AA2017 and (b) AA5086 tabs

with the highest yield stresses (AA2017) in order to avoid the adhesive failure before reaching the failure in the composite.

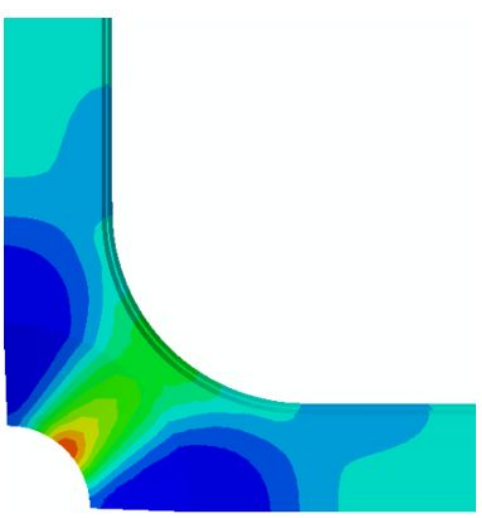

(a)

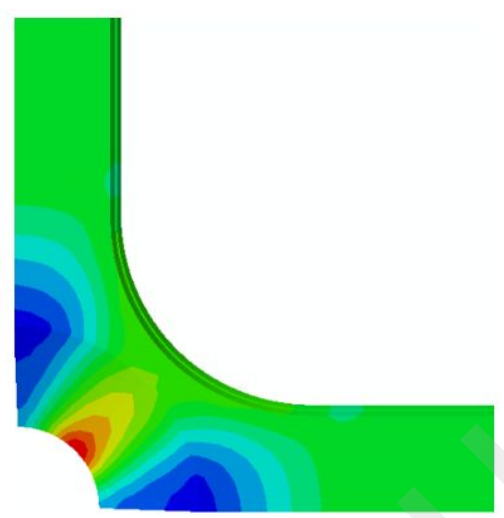

(b)

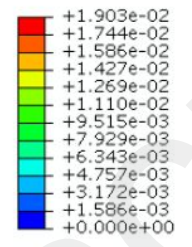
(composite.

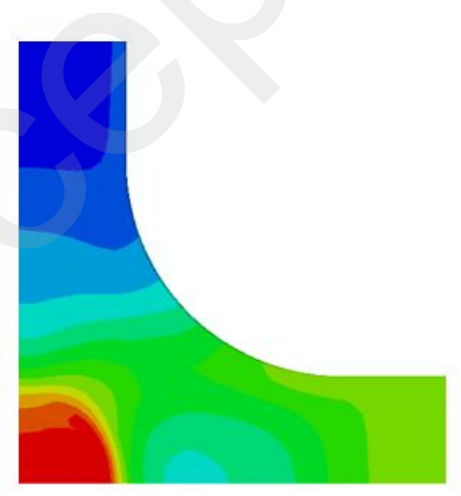

(a)

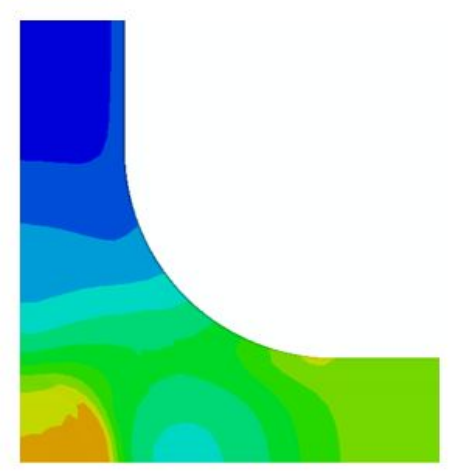

(b)

Figure 5. $\sigma_{X X}(\mathrm{MPa})$ in composite using AA5086 with a thickness of (a) $5.5 \mathrm{~mm}$ and (b) $3 \mathrm{~mm}$ 
In this section, it can be retained that the choice of the aluminum grades, for the same thickness, is based on the high level of yield stress. Meanwhile, increasing the thickness of the aluminum tabs leads to a high level of stress concentration in the central zone of the composite.

\subsection{Effect of thickness transition}

The influence of the shape of the thickness reduction in the aluminum tabs on the stress distribution in the composite is presented. A numerical comparison between linear and curved transition (radius of $24 \mathrm{~mm}$ ) is performed (the curve is tangent at the extremity of the central zone as shown in Figure 6). Figure 7 shows the $\mathrm{x}$-direction stress variation in the composite from the central point (normalized distance 0 ) towards the x-direction arm extremity (normalized distance 1) under equi-biaxial test. The results show that the curved transition gives a higher stress level in the central zone and a higher difference between the stresses in the center and the arms which emphasize the failure of the composite in the central area.
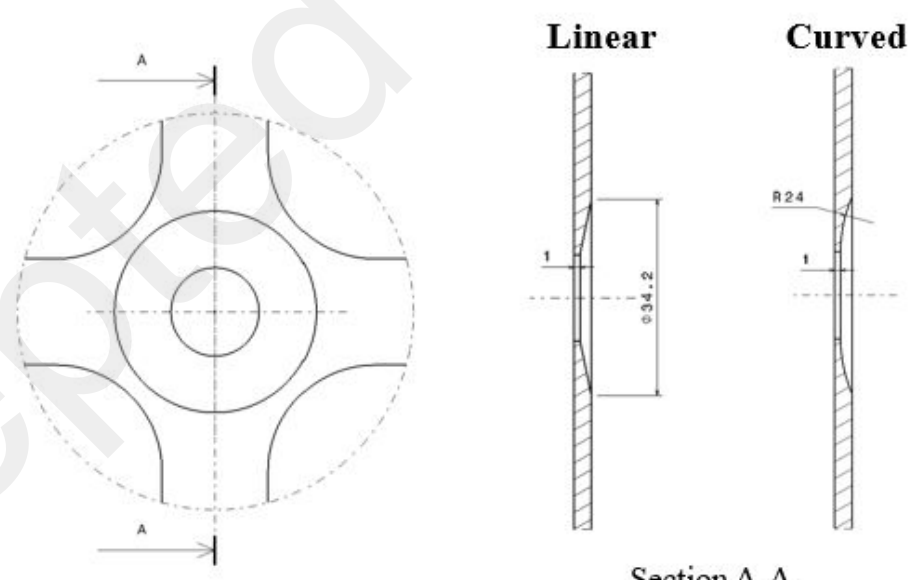

Section A-A

Figure 6. Linear and curved thickness reduction in aluminum tab (in $\mathrm{mm}$ ) 
2

3

4

5

6

7

8



Figure 7. Comparison between $\sigma_{X X}(M P a)$ results using curved and linear thickness reduction transition

\subsection{Numerical strain paths}

One of the main requirements for a successful biaxial test is obtaining failure in the central zone for different biaxial displacement ratios. The biaxial displacement ratio is defined as the ratio $U_{X} / U_{Y}$ of the displacement applied on the ends of the arms in respectively in $X$ and $Y$ directions. Assuming $3 \mathrm{~mm}$ thick AA2017 tabs, three different tensile ratios have been studied numerically (1/free, 1/0.5 and 1/1) in order to verify that the failure always appears in the central zone. Figures 8 and Figure 9 show the x-direction stress and strain distribution in the composite, respectively for all three biaxial tests. For all three biaxial ratios, stress and strain distributions show a maximum value in the central zone meaning the failure should occur in this zone. The variation of minor and major strains in the center of the composite for different biaxial ratios are presented in Figure 10. 


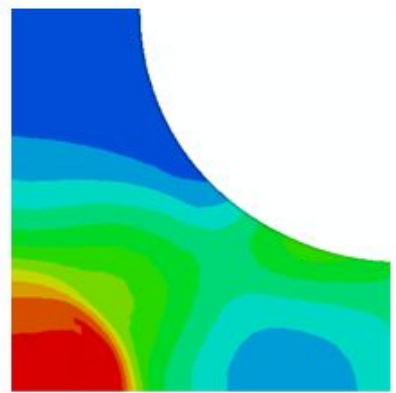

$1 /$ free

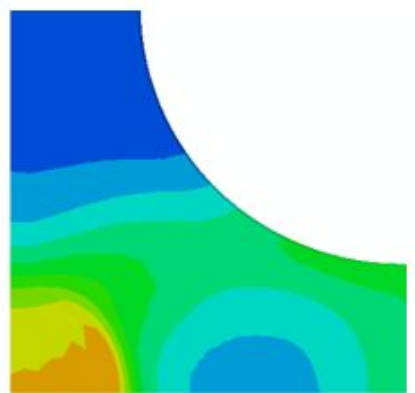

$1 / 0.5$

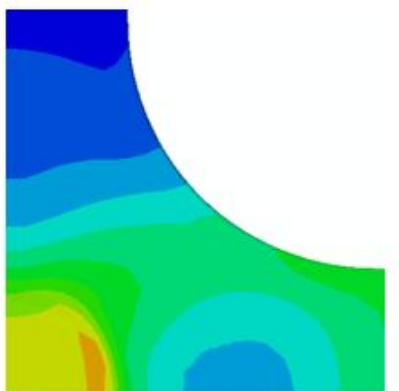

$1 / 1$

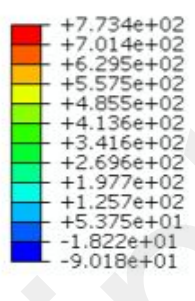

Figure 8. $\sigma_{X X}(M P a)$ in composite under different biaxial displacement ratios.

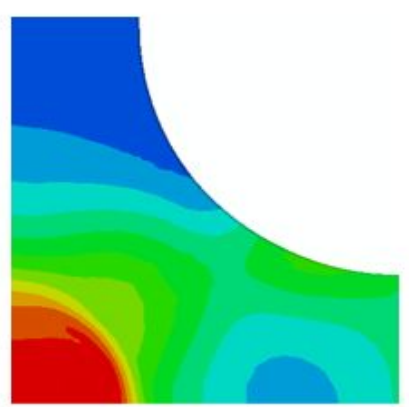

$1 /$ free

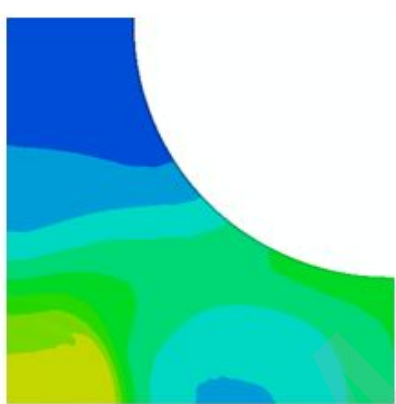

$1 / 0.5$

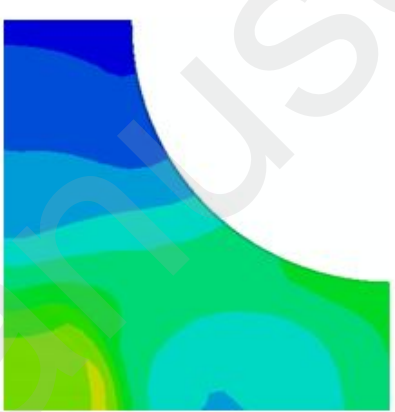

$1 / 1$

Figure 9. $\varepsilon_{X X}$ in composite under different biaxial displacement ratios

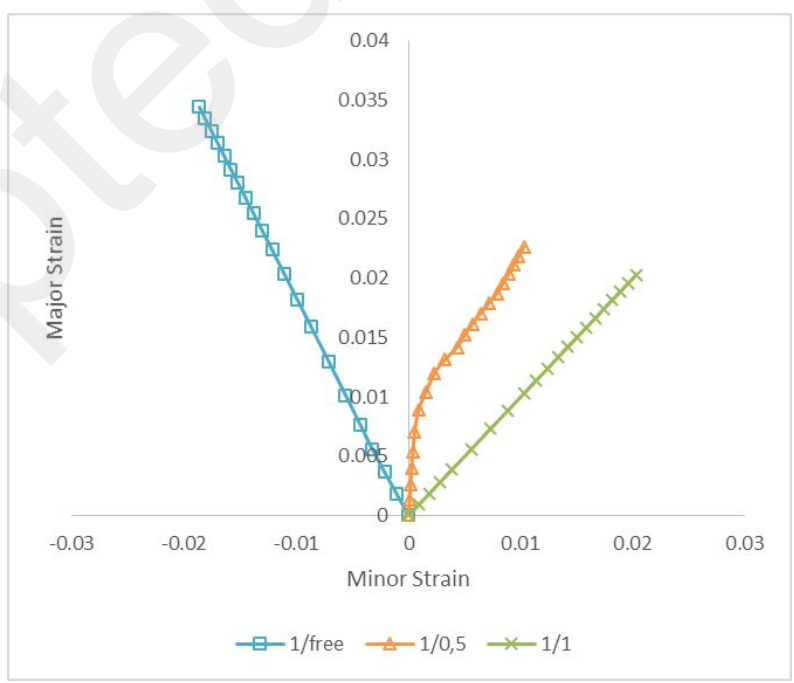

Figure 10. Major versus minor strains for different biaxial ratios 


\section{Experimental validation}

\subsection{Equipment and procedure}

The machine used in this study, (Figure 11), is a servo hydraulic machine with four independent dynamic actuators. The machine can develop $50 \mathrm{kN}$ of loading on each axis with a maximum velocity of $2 \mathrm{~m} / \mathrm{s}$ for dynamic studies. The force on each axis of the device is measured using gauge sensors. Considering the strain measurement, the digital image correlation (DIC) technic is used in order to obtain the experimental strain components. A Fastcam ultima APX-RS digital CMOS camera is placed on the top of the central zone in order to capture a consecutive number of images during the test. A frequency of 500 images per second and a resolution of $0.02 \mathrm{~mm} / \mathrm{pixel}$ are considered. The central zone of the cruciform specimen is painted white and a random pattern of black dots is realized (Figure 12). The captured images are evaluated using the software GOM Correlate, the facet size and facet distance are respectively $32 \times 32$ pixels and 32 pixels. The traction is applied on the cruciform specimen using four pins that connect the machine grips to the specimen arms.

However, the main risk in this type of test is the possibility of the adhesive failure due to a nonhomogeneous spreading or a weak adhesion between the two different materials. In order to have a better adhesive performance, the tabs inner surface have been treated by shot peening so the adhesive can penetrate in the voids generated by this type of surface treatment, and the adhesive thickness is controlled by introducing an amount of $1 \%$ of microbeads of $0.1 \mathrm{~mm}$ diameter for a better homogeneous adhesive 
spreading. The complete specimen is set under pressure at room temperature for 48 hours for the adhesive curing. Figure 13 shows the fabricated specimen.

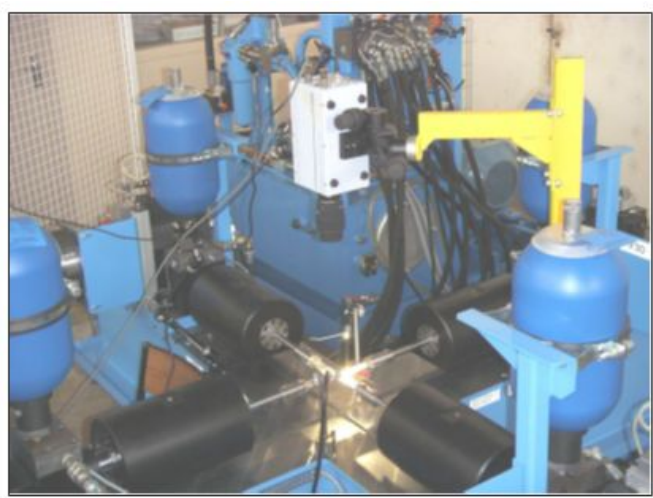

Figure 11. Biaxial testing machine

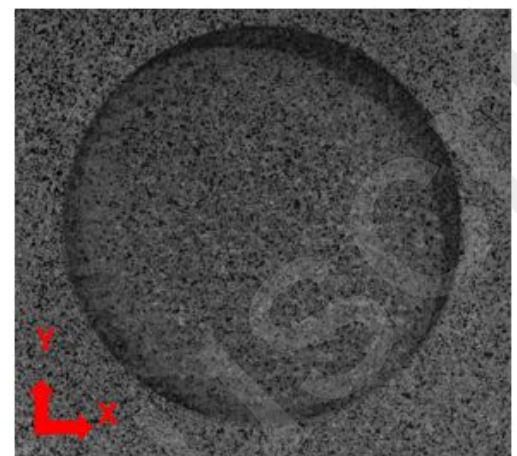

Figure 12. Specimen central zone

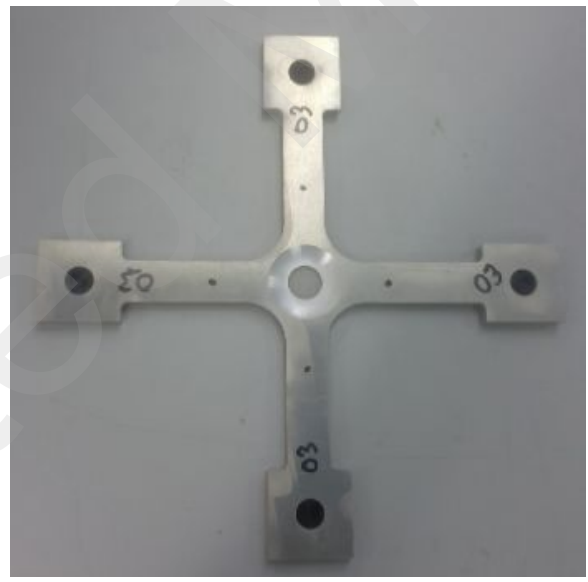

Figure 13. Assembled cruciform specimen 


\subsection{Effect of aluminum grade}

Experimental validation of previous numerical investigations is performed between both aluminum alloys AA2017 and AA5086. Because of the difference between the aluminum alloy yield stresses and in order to decrease the possibility of failure in the arms for the specimen with AA5086 tabs (as mentioned in section 2.2), a thicker AA5086 tab has been used for the experimental comparison (thickness of $5.5 \mathrm{~mm}$ ). Two static equi-biaxial tests (velocity of $1 \mathrm{~mm} / \mathrm{s}$ ) have been made using both aluminum tabs in order to select one of these tabs for the biaxial characterization test. The comparison is made until the applied displacement reaches $0.9 \mathrm{~mm}$ in each loading arm for both tests. Since the test is symmetric, the strain in both $\mathrm{x}$ and $\mathrm{y}$ directions are equal. Figure 14 shows the evolution of the strain in composite with respect to the applied displacement using both aluminum tabs. For the same amount of displacement, the composite reaches a high strain level when using AA2017 tabs (1.13\%) compared to AA5086 (0.56\%). Moreover, the experimentally measured load is introduced into the numerical model as boundary conditions in order to validate the influence of the aluminum tabs on the composite. A variable $\mathrm{R}$ has been defined as the ratio between the strain in the center of the composite using AA5086 and AA2017 (Eq. 1), a ratio R is less than one meaning that the strain in the center using AA2017 is higher than the strain using AA5086.

$$
R=\frac{\varepsilon_{\operatorname{comp}(A A 5086)}}{\varepsilon_{\operatorname{comp}(A A 2017)}}
$$

Figure 15 shows the variation of experimental and numerical $\mathrm{R}$ values with respect to the applied displacement. Results show that in both numerical and experimental tests, the strain in the central zone using AA2017 is higher than the one using AA5086. A high deformation in the composite under the same amount of displacement imposed means higher possibility of composite failure before reaching the adhesive failure. According to these results, AA2017 is chosen for the complete composite biaxial tests. 


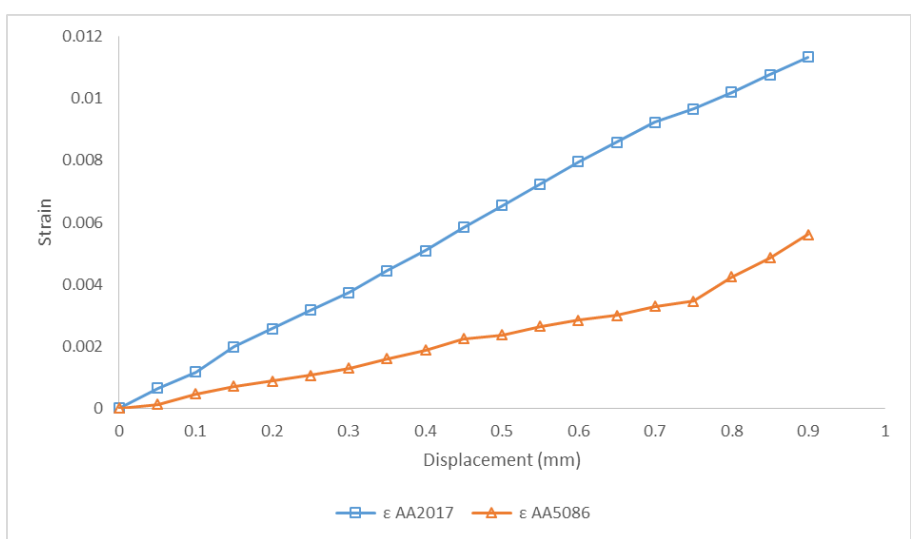

Figure 14. Composite strain at the central point of the specimen for AA2017 and AA5086

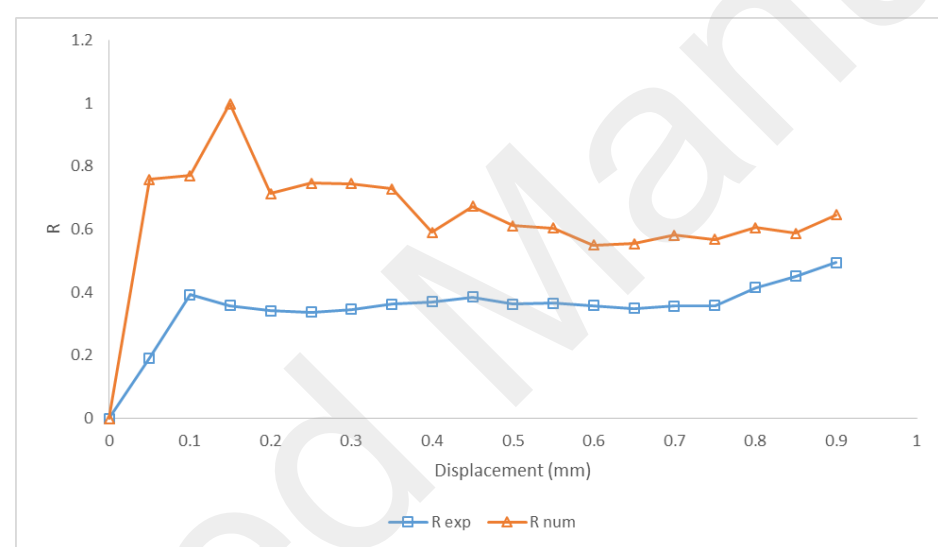

Figure 15. Variation of $\mathrm{R}$ with respect to the imposed displacement

\subsection{Experimental results for different biaxial ratios}

In this section, experimental results of biaxial tests carried out on specimens manufactured from $3 \mathrm{~mm}$ thick AA2017 tabs under different displacement ratios are presented. Static biaxial tests are performed on the cruciform specimen under the three biaxial ratios: 1/free (Test01), 1/0.5 (Test02) and 1/1 (Test03). A velocity of $1 \mathrm{~mm} / \mathrm{s}$ is applied on each arm end in the $\mathrm{x}$ direction. Figure 16 shows an example of a failed cruciform specimen for Test 01 . The stresses in the composite central zone are calculated using the 
experimental strains and the material parameters (Young modulus and Poisson ratio) according to the constitutive laws equation shown below (Eq. 2).

$$
\sigma_{x, \exp }=\frac{\left(\varepsilon_{x}+\vartheta_{x y} \varepsilon_{y}\right) E_{x}}{1-\vartheta_{x y}^{2}} \sigma_{y, \exp }=\frac{\left(\varepsilon_{y}+\vartheta_{x y} \varepsilon_{x}\right) E_{y}}{1-\vartheta_{x y}^{2}}
$$

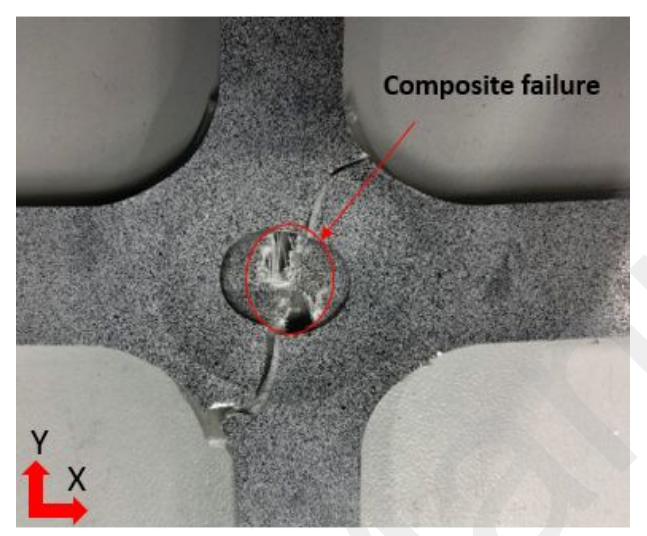

Figure 16. Cruciform specimen failure under 1/free biaxial ratio (Test01)

Since the traction velocity is constant in the $\mathrm{x}$-direction $(1 \mathrm{~mm} / \mathrm{s})$ in all the following tensile tests while the velocity in the y-direction depends on the biaxial ratio needed, load, stress and strain results will be presented with respect to the x-direction displacement $U_{X}$. Figure 17 shows the variation of the applied uniaxial load with respect to the imposed displacement, the failure of the composite occurs at a load of 35 $\mathrm{kN}$. The experimental strains and stresses in both $\mathrm{x}$ and $\mathrm{y}$ directions in the central zone of the composite are presented in Figure 18. The small negative deformation in the y direction (perpendicular to the loading direction) is due to the Poisson effect. The composite fails at a stress level of $680 \mathrm{MPa}$ and a strain level of $3.1 \%$. 


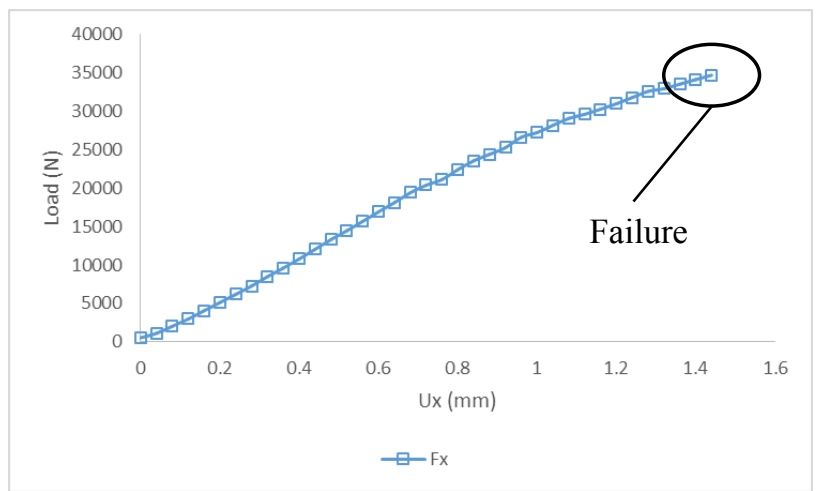

Figure 17. Load $(\mathrm{N})$ vs displacement $(\mathrm{mm})$ in Test01



(a)

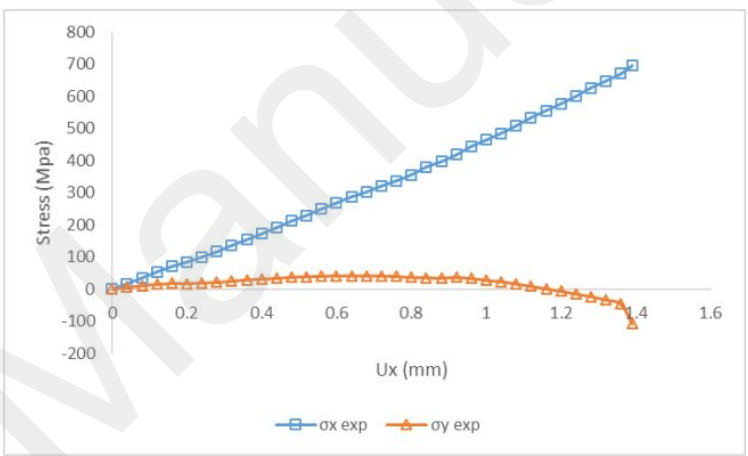

(b)

Figure 18. Strain (a) and stress (b) variation in the composite central zone for Test01

The experimental loads for the second test (Test02) are presented in Figure 19. A small decrease in the load in both directions is noticed when a displacement of $0.9 \mathrm{~mm}$ is reached in the $\mathrm{x}$ direction arm. This is due to a small crack in the cohesive (heard during the test). However, the failure didn't occur in the cohesive and the traction continues until the failure of the composite at a load $\mathrm{Fx}=40 \mathrm{kN}$ and $\mathrm{Fy}=31 \mathrm{kN}$. Figure 20 shows the strain and stresses during the test, the composite fails at a strain level of 3.1 and 1.4 $\%$ in $\mathrm{x}$ and $\mathrm{y}$ directions respectively. The calculated stresses at failure are $750 \mathrm{MPa}$ and $440 \mathrm{MPa}$ in both $\mathrm{x}$ and y directions. 


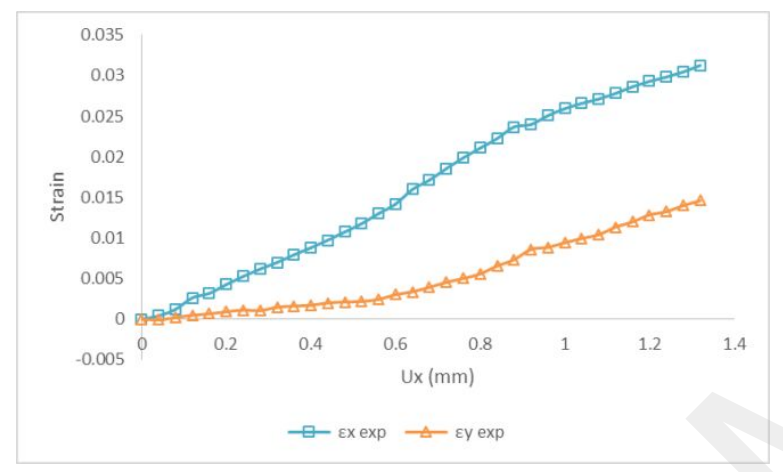

(a)

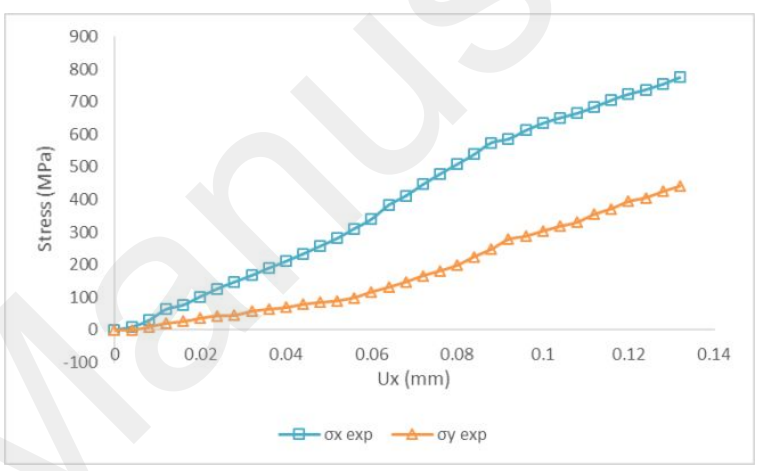

(b)

Figure 20. Strain (a) and stress (b) in the composite central zone for Test02

For the Test03, an equal displacement is applied on each arm. The equi-biaxial state of the test is shown in Figure 21 where the failure occurs at a similar load of $41 \mathrm{kN}$ on both axes. In this test, the composite fails at a high level of strain and stresses which respectively reached $2.7 \%$ and $740 \mathrm{MPa}$ in $\mathrm{x}$-direction and 3.2 $\%$ and $830 \mathrm{MPa}$ in y-direction (Figure 22). To summarize, Table 3 shows stresses and strains at failure for all tests. 




Figure 21. Load (N) vs displacement (mm) in Test03

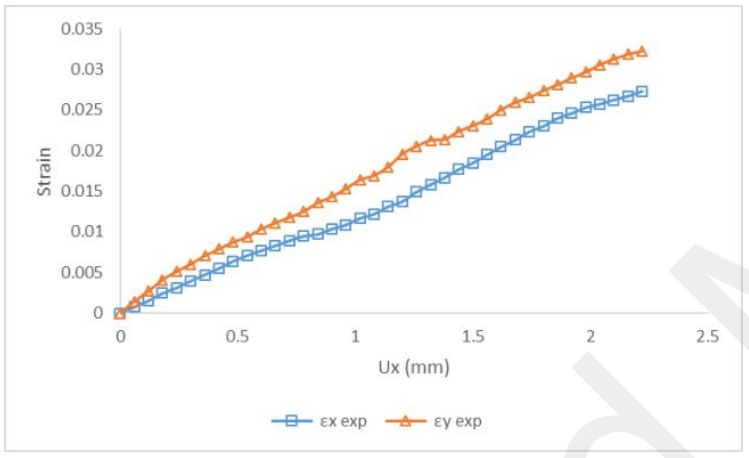

(a)

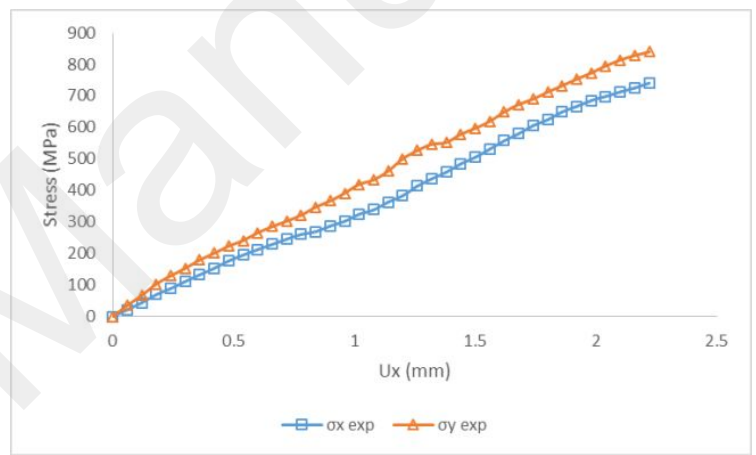

(b)

Figure 22. Strain (a) and stress (b) in the composite central zone for Test03

Table 3. Stress and strain at failure of the composite

\begin{tabular}{ccccc} 
Biaxial ratio & $\varepsilon_{x}(\%)$ & $\sigma_{x}(\mathbf{M P a})$ & $\varepsilon_{y}(\%)$ & $\sigma_{y}(\mathbf{M P a})$ \\
\hline $\mathbf{1} /$ free & 3.1 & 680 & -0.8 & -100 \\
\hline $\mathbf{1 / 0 . 5}$ & 3.1 & 750 & 1.4 & 440 \\
\hline $\mathbf{1} / \mathbf{1}$ & 2.7 & 740 & 3.2 & 830 \\
\hline
\end{tabular}

Strain paths for each biaxial ratio, at the central point of the specimen, are plotted in Figure 23 up to the onset of failure of the composite. 


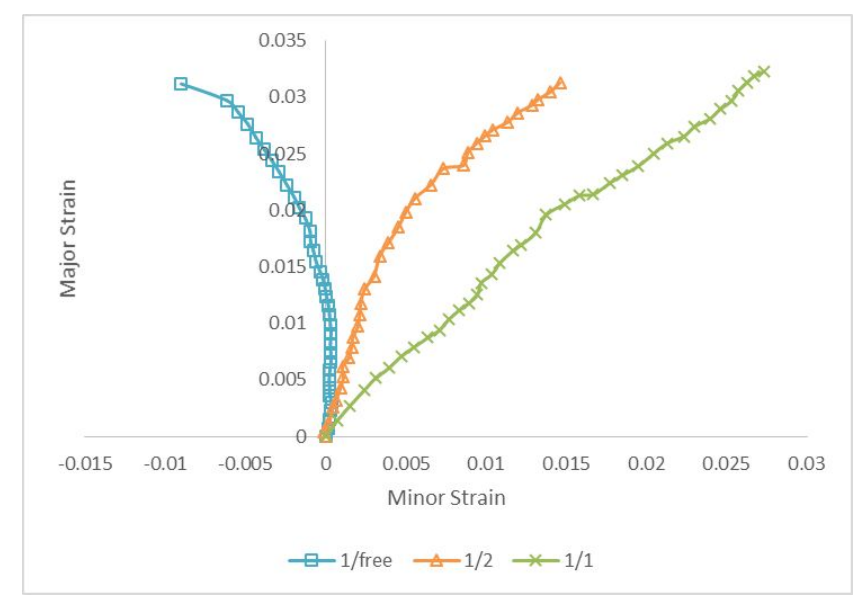

Figure 23. Strain path of glass/epoxy plain weave composite under three loading conditions

\subsection{Discussion}

The previously obtained results show that the proposed specimen shape with the concept of gluing reduced thickness aluminum tabs without machining the composite give acceptable results. The specimen fails in the central zone under different biaxial ratios. Moreover, the strain path was generated and the ultimate strain and stress at failure of the composite are obtained based on the digital image correlation technic.

Based on the experimental stresses, the first quadrant (traction/traction) of the failure envelop of the glass/epoxy plain-weave composite material is generated. Since the failure envelop is symmetric with respect to the $45^{\circ}$ line, the upper points represent the tests realized and the lower points represent their mirror image. The envelop shows that the glass/epoxy plain-weave composite strength increases under biaxial loadings (Figure 24). This biaxial strengthening, already mentioned by other researchers [28], was simply identified based on the shape of the most high-order failure theory predictions [29]. Moreover, the experimental failure envelop is compared to different non-interactive and interactive criteria such as Maximum Stress, Maximum Strain and Norris distortional energy. The maximum stress and maximum strain criteria were the most used criteria by researchers [30]. The failure is defined when either stresses in 
$\mathrm{x}$ or $\mathrm{y}$ directions (or strain in $\mathrm{x}$ or $\mathrm{y}$ directions) reach the ultimate strength of the material. In order to represent the Maximum Strain criterion in the stress space, the stresses can be calculated through Eq. 3 where $\sigma_{u, x}$ and $\sigma_{u, y}$ represent the ultimate strength of the material along $\mathrm{x}$ and $\mathrm{y}$ directions, respectively. Norris [31] proposed a failure criterion for orthotropic materials subjected to combined stresses. This criterion was validated for different orthotropic materials such as plywood and glass composite and is given for a plane stress state where $\sigma_{u, x y}$ represents the shear strength of the composite (Eq. 4). The results show that the maximum stress criterion underestimates the strength of the material under biaxial stress state. Norris distortional energy estimates well the behavior of the material under biaxial ratio of $1 / 2$ but underestimates the failure of composite under equibiaxial stress state. This is due to the fact that for the plain-weave composite, the strength of the material is equal in both $\mathrm{x}$ and $\mathrm{y}$ directions and since the shear stresses in the composite are equal to zero in this test, so Norris distortional energy criterion becomes similar to the maximum stress in the equibiaxial test for this type of materials. The maximum strain criterion correctly estimates the failure stress of the composite for the three strain paths tested.

$$
\begin{gathered}
\sigma_{x}-\vartheta_{x y} \sigma_{y}<\sigma_{u, x} \\
\sigma_{y}-\vartheta_{y x} \sigma_{x}<\sigma_{u, y} \\
\left(\frac{\sigma_{x}}{\sigma_{u, x}}\right)^{2}-\frac{\sigma_{x} \sigma_{y}}{\sigma_{u, x} \sigma_{u, y}}+\left(\frac{\sigma_{y}}{\sigma_{u, y}}\right)^{2}+\left(\frac{\sigma_{x y}}{\sigma_{u, x y}}\right)^{2}=1
\end{gathered}
$$


1

2

3

4

5

6

7

8

10

11

12

13

14

15

16

17

18

19

20

21

22

23

24

25

26

27

28

29

30

31

32

33

34

35

36

37

38

39

40

41

42

43

44

45

46

47

48

49

50

51

52

53

54

55

56

57

58

59

60

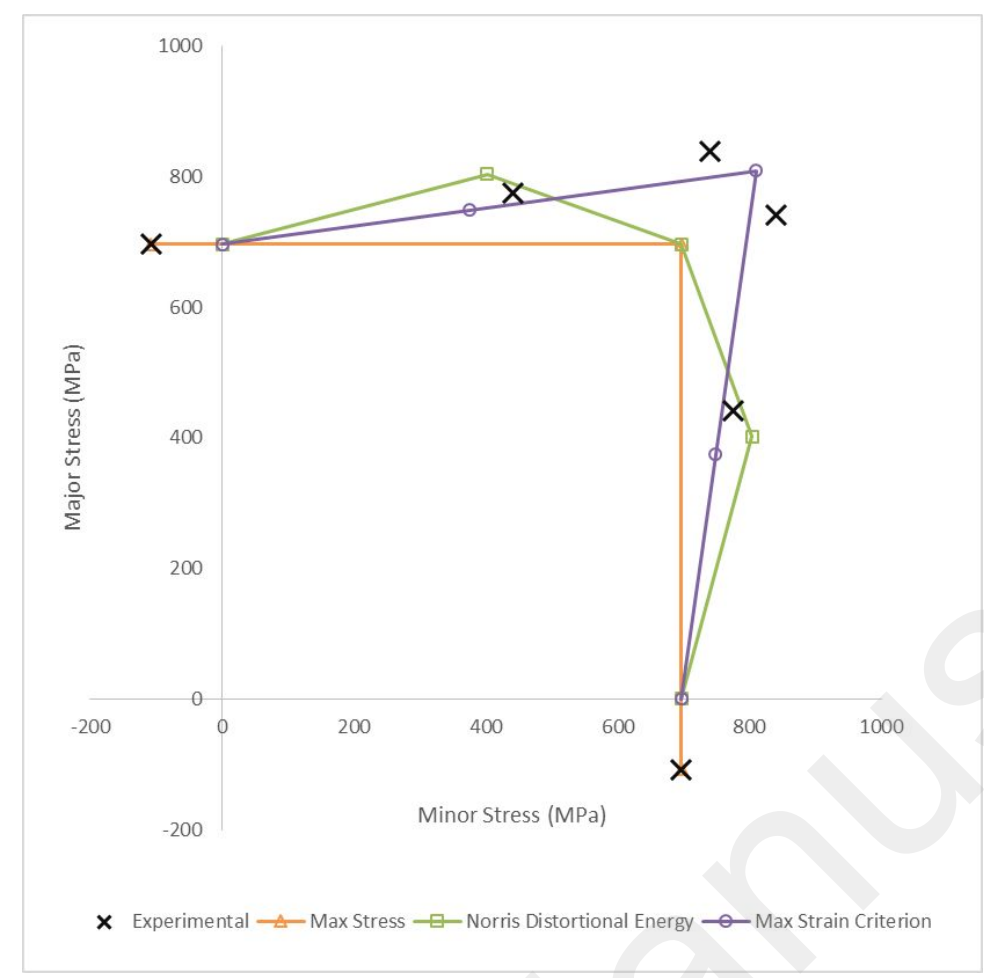

Figure 24. Biaxial failure envelop in tension/tension quadrant

\section{Conclusion}

In this work, a new cruciform specimen, dedicated to the biaxial characterization of composite materials, is designed by the finite element method and validated experimentally. The originality of the specimen is based on the combination of aluminium tabs with the composite materials to be tested. This study is motivated by the various types of cruciform specimens encountered in the literature and the difficulties to get a fracture in the central zone. The advantages of the use of aluminium tabs are: (i) ease of milling accurate and complex shapes for transition zones, (ii) no delamination in the tabs, which is common in composite tabs (iii) large admissible strains in the tabs which ensure a failure in the central zone of the composite. This method provides a robust design of cruciform specimens, the thickness of the tabs can be adjusted with the thickness of the composite. For two $3 \mathrm{~mm}$ thick AA2017 aluminum tabs glued on both sides of a constant thickness glass/epoxy composite, three different biaxial testing ratios are considered 
( $1 /$ free, $1 / 2$, and $1 / 1)$ in order to obtain the failure stresses under a wide range of loading conditions. The strains are measured in the central zone using the Digital Image Correlation technique until the failure of the composite. Based on the measured strains and the material properties, the stresses are calculated using the constitutive equations. The tensile/tensile quadrant of the failure envelop is generated and compared to different failure criteria where the Maximum Strain gives the most acceptable results compared to the other criteria.

\section{Acknowledgements}

This project has been funded with support from the Lebanese University.

\section{References}

[1] Y. S. Shin, Introduction to Composite Materials. U.S. army armament research and development center, 1984.

[2] D. Van Hemelrijck, A. Makris, C. Ramault, E. Lamkanfi, W. Van Paepegem, and D. Lecompte, "Biaxial testing of fibre-reinforced composite laminates," Proceedings of the Institution of Mechanical Engineers, Part L: Journal of Materials: Design and Applications, vol. 222, no. 4, pp. 231-239, Oct. 2008.

[3] A. S. Chen and F. L. Matthews, "A review of multiaxial/biaxial loading tests for composite materials," Composites, vol. 24, no. 5, pp. 395-406, Jul. 1993.

[4] N. I. Aniskevich, A. A. Malmeister, and Yu. O. Yanson, "Method of testing tubular specimens of polymer materials in the complex stressed state under temperature-effect conditions," Mechanics of Composite Materials, vol. 20, no. 1, pp. 118-122, 1984.

[5] M. F. S. Al-Khalil, P. D. Soden, R. Kitching, and M. J. Hinton, "The effects of radial stresses on the strength of thin-walled filament wound GRP composite pressure cylinders," International Journal of Mechanical Sciences, vol. 38, no. 1, pp. 97-120, Jan. 1995. 
[6] V. K. S. Choo and D. Hull, "Influence of Radial Compressive Stress Owing to Pressure On the Failure Modes of Composite Tube Specimens," vol. 17, pp. 344-356, 1983.

[7] R. Xiao, “A Review of Cruciform Biaxial Tensile Testing of Sheet Metals,” Exp Tech, Jan. 2019.

[8] K. J. Pascoe and J. W. R. de Villiers, "Low cycle fatigue of steels under biaxial straining," Journal of Strain Analysis, vol. 2, no. 2, pp. 117-126, Apr. 1967.

[9] I. Zidane, D. Guines, L. Léotoing, and E. Ragneau, "Development of an in-plane biaxial test for forming limit curve (FLC) characterization of metallic sheets," Meas. Sci. Technol., vol. 21, no. 5, p. 055701, May 2010.

[10] W. Liu, D. Guines, L. Leotoing, and E. Ragneau, "Identification of sheet metal hardening for large strains with an in-plane biaxial tensile test and a dedicated cross specimen," International Journal of Mechanical Sciences, vol. 101-102, pp. 387-398, Oct. 2015.

[11] "International Standard ISO 16842. Metallic materials - sheet and strip - biaxial tensile testing method using a cruciform test piece.” 2014.

[12] H. Thom, "A review of the biaxial strength of fibre-reinforced plastics," Composites Part A: Applied Science and Manufacturing, vol. 29, no. 8, pp. 869-886, Aug. 1998.

[13] P. Hopgood, J. Cook, and A. Clarke, "Multi-axial testing of planar composite specimens," in Proceedings of the 12th International Conference on Composite Materials, Paris, 1999.

[14] C. Williamson and J. Thatcher, "Investigation Into the Failure of Open Holes in Cfrp Laminates Under Biaxial Loading Conditions," in Experimental Analysis of Nano and Engineering Materials and Structures, E. E. Gdoutos, Ed. Springer, Dordrecht, 2007.

[15] D. A. Arellano Escarpita, D. Cardenas, H. Elizalde, R. Ramirez, and O. Probst, "Biaxial Tensile Strength Characterization of Textile Composite Materials," in Composites and Their Properties, InTech, 2012.

[16] J. S. Welsh and D. F. Adams, “An experimental investigation of the biaxial strength of IM6/3501-6 carbon/epoxy cross-ply laminates using cruciform specimens," Composites Part A: Applied Science and Manufacturing, vol. 33, no. 6, pp. 829-839, Jun. 2002. 
[17] J. S. Welsh, "Experimental and Numerical Failure Predictions of Biaxially Loaded Quasi-isotropic Carbon Composites," 16th International Conference on Composite Materials, 2007.

[18] A. Smits, D. Van Hemelrijck, T. P. Philippidis, and A. Cardon, "Design of a cruciform specimen for biaxial testing of fibre reinforced composite laminates," Composites Science and Technology, vol. 66, no. 7-8, pp. 964-975, Jun. 2006.

[19] A. Makris, C. Ramault, D. V. Hemelrijck, E. Lamkanfi, and W. V. Paepegem, "Biaxial Failure Envelopes for Glass Fibre Reinforced Composite Laminates,” p. 12, 2009.

[20] A. Makris, C. Ramault, D. V. Hemelrijck, E. Lamkanfi, and W. V. Paepegem, "Damage evolution on composite cruciform specimens under quasi-static biaxial loading," 17th International Conference on Composite Materials, 2009.

[21] C. Ramault, E. Lamkanfi, and W. V. Paepegem, "Effect of tab design on the strain distribution of a biaxially loaded cruciform composite specimen," 17th International Conference on Composite Materials, 2009.

[22] E. Lamkanfi, W. Van Paepegem, J. Degrieck, C. Ramault, A. Makris, and D. Van Hemelrijck, "Strain distribution in cruciform specimens subjected to biaxial loading conditions. Part 2: Influence of geometrical discontinuities," Polymer Testing, vol. 29, no. 1, pp. 132-138, Feb. 2010.

[23] J. Ash and J. Welsh, "Biaxial Strength Measurements of IM7/977-2 Carbon/Epoxy Laminates Using Tabbed Cruciform Specimens," in 45th AIAA/ASME/ASCE/AHS/ASC Structures, Structural Dynamics \&amp; Materials Conference, Palm Springs, California, 2004.

[24] A. S. Torres and A. K. Maji, "The development of a modified bi-axial composite test specimen," Journal of Composite Materials, vol. 47, no. 19, pp. 2385-2398, Sep. 2013.

[25] M. J. Hinton, A. S. Kaddour, and P. D. Soden, Failure Criteria in Fibre Reinforced Polymer Composites: The World-Wide Failure Exercice 1st edition. Oxford, UK: Elsevier, 2004.

[26] A. Kaddour, M. Hinton, P. Smith, and S. Li, “The background to the third world-wide failure exercise," Journal of Composite Materials, vol. 47, no. 20-21, pp. 2417-2426, Sep. 2013. 
[27] A. Kobeissi, L. Leotoing, D. Guines, and P. Rahme, "Numerical Investigation on Composite Cruciform Shape for the Biaxial Characterization Test," in Proceedings of the 18th European Conference on Composite Materials, Athens, Greece, 2018.

[28] J. S. Welsh, J. S. Mayes, C. T. Key, and R. N. McLaughlin, "Comparison of MCT Failure Prediction Techniques and Experimental Verification for Biaxially Loaded Glass Fabric-reinforced Composite Laminates," Journal of Composite Materials, vol. 38, no. 24, pp. 2165-2181, Dec. 2004.

[29] M. J. Hinton, A. S. Kaddour, and P. D. Soden, "A comparison of the predictive capabilities of current failure theories for composite laminates, judged against experimental evidence," Composites Science and Technology, vol. 62, no. 12-13, pp. 1725-1797, Sep. 2002.

[30] C. T. Sun, B. J. Quinn, J. Tao, and D. W. Oplinger, "Comparative Evaluation of Failure Analysis Methods for Composite Laminates,” NASA, DOT/FAA/AR-95/109, 1996.

[31] C. B. Norris, "Strength of orthotropic materials subjected to combined stress, Laboratory report 1816. Washington,: US forest products, 1962. 